\title{
Effects of high inclusion of soybean hulls on apparent total tract macronutrient digestibility, fecal quality, and fecal fermentative end-product concentrations in extruded diets of adult dogs
}

\author{
Katelyn B. Detweiler,* Fei He,* Heather F. Mangian,* Gary M. Davenport, ${ }^{\dagger}$ and \\ Maria R. C. de Godoy*,1 \\ *Department of Animal Sciences, University of Illinois, Urbana, IL 61801; \\ and ${ }^{\dagger}$ Archer Daniels Midland Company, Decatur, IL 62526
}

\begin{abstract}
Soybean hulls (SBH) are a fiber-rich co-product of the soybean oil extraction process that corresponds to $8 \%$ of the soybean seed. Despite being readily available and priced competitively, SBH are underutilized in monogastric nutrition. Thus, the objective of this study was to evaluate $\mathrm{SBH}$ as a dietary fiber in canine diets. Four diets were formulated with either $\mathrm{SBH}$, beet pulp (BP), or cellulose (CL) as the main source of dietary fiber (15\% total dietary fiber [TDF]), with the control diet formulated with no supplemental fiber (NF). Animal procedures were approved by the University of Illinois Institutional Animal Care and Use Committee. Eight adult female Beagle (mean age $=4.6 \pm 0.6 \mathrm{yr}$; mean $\mathrm{BW}=12.8 \pm 1.7 \mathrm{~kg}$ ) were used in a replicated $4 \times$ 4 Latin square design. Each period consisted of $14 \mathrm{~d}$, with $10 \mathrm{~d}$ of diet adaptation followed by 4 $\mathrm{d}$ of total fecal and urine collections. At the end of each period, a blood sample was collected and analyzed for serum chemistry. Food was offered twice daily and fed to maintain body weight. Food intake $(\mathrm{g} / \mathrm{d})$ on a dry matter basis (DMB) did not differ among treatments. Fecal score was lower $(P<0.05)$ for dogs fed CL $(2.0)$ in contrast with other dietary treatments (2.3), using a 5-point
\end{abstract}

scale $(1=$ hard, dry pellets; $5=$ diarrhea $)$. Fecal as-is and DM output did not differ for dogs fed $\mathrm{BP}, \mathrm{CL}$, or $\mathrm{SBH}$, and were approximately $50 \%$ greater $(P<0.05)$ than dogs fed NF. Apparent total tract digestibility (ATTD) of dry matter, organic matter, and gross energy were greater $(P<0.05)$ for dogs fed NF when compared with dogs fed BP, CL, or SBH. Dogs fed CL had greater $(P<0.05)$ AHF ATTD $(94 \%)$ compared with all other treatments $($ mean $=91 \%)$. Dogs fed CL and NF had greater $(P<0.05)$ CP ATTD, $87 \%$ and $86 \%$, respectively, while dogs fed $\mathrm{SBH}$ were intermediate $(83 \%)$ and dogs fed BP were lowest $(79 \%)$. Total short-chain fatty acid (SCFA) concentration was greatest in dogs fed BP $(582.5 \mu \mathrm{mol} / \mathrm{g})$ and SBH $(479.7 \mu \mathrm{mol} / \mathrm{g})$ when compared with NF and CL (267.0 and $251.1 \mu \mathrm{mol} / \mathrm{g}$, respectively). Serum metabolites were within-reference ranges and dogs remained healthy throughout the study. In conclusion, $\mathrm{SBH}$ resulted in similar macronutrient ATTD when compared with BP and CL. Dogs fed $\mathrm{SBH}$ were also observed to have an increase in fecal SCFA concentration. In general, high level addition of SBH were well-utilized by the dog, resulting in no untoward effects on dog health, nutrient digestibility, or fecal characteristics.

Key words: canine, dietary fiber, gut health, nutrient digestion, pet food

(C) The Author(s) 2019. Published by Oxford University Press on behalf of the American Society of Animal Science. All rights reserved. For permissions, please e-mail: journals.permissions@oup.com.

J. Anim. Sci. 2019.97:1027-1035 doi: 10.1093/jas/skz015

${ }^{1}$ Corresponding author: mgodoy2@illinois.edu Received October 11, 2018.

Accepted January 8, 2019.

\section{INTRODUCTION}

The most recent pet census, published in 2018, indicates that there are approximately 89.7 million 
pet dogs in the United States (APPA, 2018). Due to pet parents acknowledging their pet as a family member, owners have developed a strong emotional bond with their pets and seek ways to increase their health and longevity. Dietary fibers have gained renewed interest in the pet food industry as a functional ingredient, as they have several health benefits such as control of glucose homeostasis, lowering caloric density of foods and aiding in weight loss, improving digestive health, improving fecal quality, and increasing production of short-chain fatty acids (SCFA), which are used as an energy source for the colonocytes and host (Banta et al., 1979; Fahey et al., 1992; Massimino et al., 1998; Swanson et al., 2002.

Soybean hulls (SBH) are a fiber-rich co-product of the soybean oil extraction process. In the United States, soybean production is increasing, and it is followed by a steady decrease in yearly costs (USDA 2017), resulting in copious amounts of soybean co-products being readily available.

However, no research has been done to evaluate the effects of $\mathrm{SBH}$ in canine diets with high concentrations of dietary fiber. Hence, the objective of this study was to evaluate the effects of $\mathrm{SBH}$ on food intake, apparent total tract macronutrient digestibility, and fecal fermentative end-products of dogs compared with a no fiber diet (control) and two standard fibers, beet pulp and cellulose. It was hypothesized that intake of SBH would beneficially shift fermentative end-product production, resulting in an intermediate fermentative profile when compared with BP and CL diets, without compromising nutrient digestibility and animal health.

\section{MATERIALS AND METHODS}

All animal care procedures were approved by the University of Illinois Institutional Animal Care and Use Committee prior to animal experimentation.

\section{Animals and Diets}

Eight adult female Beagle (age $=4.6 \pm 0.6 \mathrm{yr}$; body weight $=12.8 \pm 1.7 \mathrm{~kg}$ ) were used. The dogs were housed in a temperature- and light-controlled room (approximately $21{ }^{\circ} \mathrm{C}, 14 \mathrm{~h}$ light:10 h dark) at the Veterinary Medicine Basic Sciences building at the University of Illinois at Urbana-Champaign. Dogs were housed individually in pens (1.2 m wide $\times 1.8 \mathrm{~m}$ long $\times 1.8 \mathrm{~m}$ high) and socialized in groups with toy enrichment. Pens allowed for nose-nose contact between dogs in adjacent runs and visual contact with all dogs in the room. Water was available ad libitum throughout the study. During the collection phase, dogs were housed individually in metabolic cages and given the same access to food and water, and allowed individual social interaction daily.

Four experimental diets were fed to the dogs twice daily (0800 and 1600) to maintain body weight (BW). Food intake and refusal were recorded after each meal throughout the duration of the study. Food intake was determined based on previous individualized food intake and metabolizable energy (ME) requirement records. The control diet contained no supplemental dietary fiber (no fiber; NF), while the three fiber diets were formulated with either beet pulp (BP), cellulose $(\mathbf{C L})$, or $\mathrm{SBH}$ as the main source of dietary fiber added at the expense of chicken by-product meal and brewer's rice (Table 1). The diets were formulated to be complete and balanced according to AAFCO (2016) for adult dogs at maintenance, and to have a similar nutrient composition (Table 2). Macronutrients were targeted to contain approximately $30 \%$ crude protein (CP), 12\% acid hydrolyzed fat (AHF), and 15\% total dietary fiber (TDF), except for the NF diet (5\% TDF). Diets were extruded at the Kansas State University Bioprocessing and Industrial Value-Added Program facility (Manhattan, KS).

\section{Experimental Design and Sample Collection}

This experiment followed a replicated $4 \times 4$ Latin square design so each dog served as its own control. Each experimental period consisted of $14 \mathrm{~d}$. The first $10 \mathrm{~d}$ served as the diet adaption phase, followed by 4 $\mathrm{d}$ of total fecal and urine collection. Throughout the collection phase, all feces were collected, scored using the following 5-point scale: 1 = hard, dry pellets; small hard mass; $2=$ hard formed, remains firm and soft; 3 = soft, formed and moist stool, retains shape; 4 = soft, unformed stool; assumes shape of container; $5=$ watery, liquid that can be poured. All samples were stored in $\mathrm{a}-20{ }^{\circ} \mathrm{C}$ freezer until analysis. Within each experimental period and during the last $2 \mathrm{~d}$ of fecal collection, one fresh fecal sample was collected from each dog within $15 \mathrm{~min}$ of defecation. The fresh sample was scored, weighed, and measured for $\mathrm{pH}$. Aliquots of the sample were frozen immediately at $-20{ }^{\circ} \mathrm{C}$ to be used to determine phenol and indole concentrations. Additionally, an additional aliquot was placed in $2 \mathrm{~N}$ hydrochloric acid and frozen at $-20{ }^{\circ} \mathrm{C}$ until analysis of SCFA, branched-chain fatty acids (BCFA), and ammonia concentrations. Total urine output was collected from day 11-14 
Table 1. Ingredient composition of experimental diets containing select fiber sources

\begin{tabular}{|c|c|c|c|c|}
\hline \multirow[b]{2}{*}{ Item, $\%$ as-is basis } & \multicolumn{4}{|c|}{ Treatments } \\
\hline & No fiber & Beet pulp & Cellulose & Soybean hulls \\
\hline Chicken by-product meal & 31.1 & 31.7 & 33.3 & 30.7 \\
\hline Corn gluten meal & 8.2 & 8.2 & 8.2 & 8.2 \\
\hline Brewer's rice & 46.0 & 28.8 & 33.5 & 31.5 \\
\hline Corn, whole, ground & 4.1 & 4.1 & 4.1 & 4.1 \\
\hline Choice white grease & 8.0 & 8.0 & 8.0 & 8.0 \\
\hline Beet pulp ${ }^{1}$ & 0.0 & 16.6 & 0.0 & 0.0 \\
\hline Cellulose $^{1}$ & 0.0 & 0.0 & 10.3 & 0.0 \\
\hline Soybean hulls ${ }^{1}$ & 0.0 & 0.0 & 0.0 & 15.0 \\
\hline Salt & 0.5 & 0.5 & 0.5 & 0.5 \\
\hline Potassium chloride & 0.45 & 0.45 & 0.45 & 0.45 \\
\hline Taurine & 0.2 & 0.2 & 0.2 & 0.2 \\
\hline Mineral premix ${ }^{2}$ & 0.18 & 0.18 & 0.18 & 0.18 \\
\hline Vitamin premix $^{3}$ & 0.18 & 0.18 & 0.18 & 0.18 \\
\hline Choline chloride & 0.13 & 0.13 & 0.13 & 0.13 \\
\hline
\end{tabular}

${ }^{1}$ Lortscher Animal Nutrition Inc., Bern, KS.

${ }^{2}$ Provided per kg diet: $17.4 \mathrm{mg}$ manganese $\left(\mathrm{MnSO}_{4}\right), 284.3 \mathrm{mg}$ iron $\left(\mathrm{FeSO}_{4}\right), 17.2 \mathrm{mg}$ copper $\left(\mathrm{CuSO}_{4}\right), 2.2 \mathrm{mg}$ cobalt $\left(\mathrm{CoSO}_{4}\right), 166.3 \mathrm{mg}$ zinc $\left(\mathrm{ZnSO}_{4}\right), 7.5 \mathrm{mg}$ iodine $(\mathrm{KI})$, and $0.2 \mathrm{mg}$ selenium $\left(\mathrm{Na}_{2} \mathrm{SeO}_{3}\right)$.

${ }^{3}$ Provided per kg diet: 11,000 IU vitamin A acetate; $900 \mathrm{IU}$ vitamin D3; $57.5 \mathrm{IU}$ vitamin E acetate; $0.6 \mathrm{mg}$ vitamin $\mathrm{K} ; 7.6 \mathrm{mg}$ thiamine $\mathrm{HCl}$; $11.9 \mathrm{mg}$ riboflavin; $18.5 \mathrm{mg}$ pantothenic acid, calcium; $93.2 \mathrm{mg}$ niacin; $6.6 \mathrm{mg}$ pyridoxine $\mathrm{HCl} ; 12.4 \mathrm{mg}$ biotin; $1,142.1 \mu \mathrm{g}$ folic acid; $164.9 \mu \mathrm{g}$ vita$\min \mathrm{B} 12,0.1 \%$ mannitol.

Table 2. Analyzed chemical composition and energy content of experimental diets

\begin{tabular}{|c|c|c|c|c|}
\hline \multirow[b]{2}{*}{ Item } & \multicolumn{4}{|c|}{ Treatments } \\
\hline & No Fiber & Beet Pulp & Cellulose & Soybean Hulls \\
\hline \multirow[t]{2}{*}{ Dry matter, $\%$} & 90.2 & 93.3 & 95.8 & 94.1 \\
\hline & \multicolumn{3}{|c|}{$\%$, DM basis } & \\
\hline Organic matter, $\%$ & 93.1 & 92.7 & 93.2 & 92.9 \\
\hline Crude protein, $\%$ & 31.7 & 31.4 & 32.6 & 30.9 \\
\hline Acid-hydrolyzed fat, $\%$ & 11.9 & 13.0 & 15.9 & 13.3 \\
\hline TDF, $1 \%$ & 5.0 & 17.3 & 14.7 & 14.3 \\
\hline Insoluble, $\%$ & 2.4 & 10.1 & 12.1 & 12.4 \\
\hline Soluble, $\%$ & 2.6 & 7.2 & 2.6 & 1.9 \\
\hline $\mathrm{GE},{ }^{1} \mathrm{kcal} / \mathrm{g}$; measured & 5.0 & 5.0 & 5.2 & 5.0 \\
\hline $\mathrm{ME},{ }^{2} \mathrm{kcal} / \mathrm{g}$; calculated & 3.7 & 3.3 & 3.5 & 3.4 \\
\hline
\end{tabular}

${ }^{1} \mathrm{TDF}=$ total dietary fiber; $\mathrm{GE}=$ gross energy (measured by bomb calorimetry).

${ }^{2} \mathrm{ME}=$ metabolizable energy; $\mathrm{ME}=8.5 \mathrm{kcal} \mathrm{ME} / \mathrm{g}$ fat $+3.5 \mathrm{kcal} \mathrm{ME} / \mathrm{g} \mathrm{CP}+3.5 \mathrm{kcal} \mathrm{ME} / \mathrm{g}$ nitrogen-free extract.

in containers containing $5 \mathrm{~mL}$ of $2 \mathrm{~N}$ hydrochloric acid for immediate acidification upon urination. Acidified urine samples were subsampled and stored at $-20{ }^{\circ} \mathrm{C}$ until analysis. Additionally, at the end of every period, dogs were fasted overnight (approximately $12 \mathrm{~h}$ ) prior to blood sample collection $(8 \mathrm{~mL})$. Blood was collected in BD Vacutainer serum separator tubes and EDTA tubes (Becton, Dickinson and Company, Franklin Lakes, NJ) for serum chemistry and complete blood count, respectively. All samples were analyzed by the University of Illinois Veterinary School Diagnostics Laboratory using a Hitachi 911 clinical chemistry analyzer (Roche Diagnostics, Indianapolis, IN).

\section{Sample Preparation and Chemical Analyses}

Food and fecal samples were used to determine apparent total tract digestibility (ATTD) of macronutrients. Samples were dried at $55^{\circ} \mathrm{C}$ in a forced-air oven and ground in a Wiley mill (model 4; Thomas Scientific, Swedesboro, NJ) through a $2-\mathrm{mm}$ screen. Diet and fecal samples were analyzed for dry matter (DM), organic matter (OM), and ash according to AOAC (2006; methods 934.01 and 942.05). Crude protein content of the diets and fecal samples was calculated from Leco (TruMac N, Leco Corporation, St. Joseph, MI) total nitrogen values according to AOAC (2006; method 992.15). Total 
lipid content was determined by acid hydrolysis followed by ether extraction according to the methods of the American Association of Cereal Chemists (1983) and Budde (1952). Diet and fecal TDF content were analyzed by Eurofins (Des Moines, IA) according to AOAC (1995, Method 991.43). Diet, fecal, and urine samples were measured for gross energy (GE) by bomb calorimeter (Model 6200, Parr Instruments Co., Moline, IL). Urine GE values were used to calculate ME.

Fecal samples were analyzed for phenol and indole concentrations using gas chromatography according to the method of Flickinger et al. (2003); SCFA and BCFA concentrations using gas chromatography according to Erwin et al. (1961); and ammonia concentrations were measured according to the method of Chaney and Marbach (1962).

Each analysis was done in duplicate, a 5\% error (or lower) was accepted between duplicates. Otherwise, analysis was repeated.

\section{Statistical Analysis}

All data were analyzed using the Mixed Models procedure of SAS (SAS Institute Inc., version 9.4, Cary, NC), with diet as a fixed effect and dog as the random effect. Fecal score was analyzed using the GLIMMIX procedure of SAS. Data normality was analyzed using PROC UNIVARIATE. Differences among treatments were determined using a Fisher-protected least significant difference test with a Tukey adjustment to control for type-1 experiment-wise error. A probability of $P$ $\leq 0.05$ was accepted as statistically significant and reported pooled SEM were determined according to the Mixed Models procedure of SAS.

\section{RESULTS AND DISCUSSION}

Serum chemistry and complete blood count were analyzed for each dog to ensure that the experimental diets did not have any negative implications on health status. There were no differences among treatments and all values were within the corresponding reference ranges. A previous study done by Scheraiber et al. (2016) evaluated blood biochemical profile of dogs fed a diet with $16 \%$ SBH $(25 \%$ TDF) or without SBH (control diet, $14 \%$ TDF). Similar to our findings, the authors did not observe differences between dietary treatments for cholesterol, triglycerides, or glucose. Likewise, those metabolites were within reference range for healthy adult dogs. In the study presented herein, complete blood count were also analyzed and deemed normal for adult healthy dogs (data not shown).

\section{Diet, Food Intake, and Fecal Characteristics}

All four experimental diets had relatively similar chemical composition (Table 2). Dry matter content ranged from 90.2 to $95.8 \%$. On a DM basis, OM among all experimental diets was approximately $93 \%$ and average crude protein was $31.7 \%$. The CL treatment had slightly greater AHF content $(15.9 \%)$ in contrast with NF $(11.9 \%)$, BP $(13.0 \%)$, and $\mathrm{SBH}(13.3 \%)$, which was reflected in the greater GE content of the CL diet. The variation observed in the AHF content of these diets was due to deviations in the amount of fat dispersed on the kibbles during the fat coating step during diet manufacturing. The NF diet was formulated to have 5.0\% $\mathrm{TDF}$ and the fiber treatments to have $15 \% \mathrm{TDF}$. This was achieved for the most part. The BP diet had a slightly greater amount of TDF (17.3\%) than expected. This result is not surprising as TDF content of BP can be highly variable (Fahey et al., 1990; Sunvold et al., 1995). As intended, the soluble and insoluble fractions of TDF varied among the dietary treatments, with $\mathrm{BP}$ diet having a greater concentration of soluble fiber $(7.2 \%)$ in comparison with CL $(2.6 \%)$ or SBH $(1.9 \%)$ diets.

Food intake (g/d DM basis) did not differ $(P>$ 0.05 ) among the four dietary treatments (Table 3$)$. Dogs fed the CL treatment had a lower $(P<0.05)$ fecal score (2.0) compared to the other three treatments (2.3). All of these scores, however, were within an acceptable range using a 5-point scale. In addition, similar fecal score (2.12) has been reported for dogs fed a diet formulated with $12 \%$ BP and containing 13\% TDF (Kroger et al., 2017). Fecal as-is and DM output (g/d) did not differ $(P>0.05)$ in dogs fed fiber-added diets; however, they were greater than dogs fed the NF diet (Table 3). Numerically, BP had the greatest fecal output expressed on an as-is basis $(85.5 \mathrm{~g} / \mathrm{d})$ compared with CL, and SBH (66.0 and $69.2 \mathrm{~g} / \mathrm{d}$, respectively). But, when expressed on a DM basis, BP fecal output $(27.9 \mathrm{~g} / \mathrm{d})$ was similar to CL and SBH (31.6 and $27.2 \mathrm{~g} / \mathrm{d})$. This indicates that the BP diet had a greater water holding capacity due to the greater concentration of soluble fibers. This property has also been previously reported in sows fed diets containing 14\% BP and canines fed diets containing $7.5 \% \mathrm{BP}$ as the main source of dietary fiber (Burkhalter et al., 2001; Serena et al., 2008). 
Table 3. Food intake and fecal characteristics of dogs fed diets containing select fiber sources

\begin{tabular}{|c|c|c|c|c|c|c|}
\hline \multirow[b]{2}{*}{ Item $^{1}$} & \multicolumn{4}{|c|}{ Treatments } & \multirow[b]{2}{*}{ SEM } & \multirow[b]{2}{*}{$P$-value } \\
\hline & No Fiber & Beet Pulp & Cellulose & Soybean Hulls & & \\
\hline \multicolumn{7}{|l|}{ Food intake } \\
\hline $\mathrm{g} / \mathrm{d}, \mathrm{DM}$ basis & 112.5 & 117.5 & 140.5 & 116.3 & 17.64 & 0.2218 \\
\hline \multicolumn{7}{|l|}{ Fecal characteristics/output } \\
\hline Fecal score $^{1}$ & $2.3^{\mathrm{a}}$ & $2.3^{\mathrm{a}}$ & $2.0^{\mathrm{b}}$ & $2.3^{\mathrm{a}}$ & 0.08 & 0.0002 \\
\hline Fecal output, as-is, g/d & $35.9^{\mathrm{b}}$ & $85.5^{\mathrm{a}}$ & $66.0^{\mathrm{a}}$ & $69.2^{\mathrm{a}}$ & 11.01 & 0.0001 \\
\hline Fecal output, DM basis, g/d & $15.9^{\mathrm{b}}$ & $27.9^{\mathrm{a}}$ & $31.6^{\mathrm{a}}$ & $27.2^{\mathrm{a}}$ & 3.85 & 0.0002 \\
\hline Fecal DM, \% & $44.7^{\mathrm{a}}$ & $33.8^{\mathrm{c}}$ & $48.7^{\mathrm{a}}$ & $39.4^{\mathrm{b}}$ & 1.68 & 0.0001 \\
\hline
\end{tabular}

${ }^{1} \mathrm{DM}=$ dry matter; Fecal scores: $1=$ hard, dry pellets; small hard mass; 2 = hard formed, remains firm and soft; 3 = soft, formed and moist stool, retains shape; $4=$ soft, unformed stool; assumes shape of container; $5=$ watery, liquid that can be poured.

${ }^{a, b}$ Means in the same row without common superscript letters denote a significant difference $(P<0.05)$

Table 4. Total tract apparent macronutrient and energy digestibilities of dogs fed diets containing different fiber sources

\begin{tabular}{|c|c|c|c|c|c|c|}
\hline \multirow[b]{2}{*}{ Item } & \multicolumn{4}{|c|}{ Treatments } & \multirow[b]{2}{*}{ SEM } & \multirow[b]{2}{*}{$P$-value } \\
\hline & No fiber & Beet pulp & Cellulose & Soybean hulls & & \\
\hline \multicolumn{7}{|c|}{ Nutrient and energy digestibilities, $\%$} \\
\hline \multirow[t]{2}{*}{$\mathrm{DM}^{1}$} & $85.4^{\mathrm{a}}$ & $76.2^{\mathrm{b}}$ & $77.2^{\mathrm{b}}$ & $79.6^{\mathrm{b}}$ & 0.82 & 0.0001 \\
\hline & & & $\%, \mathrm{DM}$ & & & \\
\hline Organic matter & $90.1^{\mathrm{a}}$ & $80.9^{\mathrm{b}}$ & $80.5^{\mathrm{b}}$ & $79.9^{\mathrm{b}}$ & 0.73 & 0.0001 \\
\hline Crude protein & $85.8^{\mathrm{a}}$ & $78.8^{\mathrm{c}}$ & $87.1^{\mathrm{a}}$ & $83.3^{\mathrm{b}}$ & 0.82 & 0.0001 \\
\hline Acid-hydrolyzed fat & $90.9^{\mathrm{b}}$ & $91.2^{\mathrm{b}}$ & $94.3^{\mathrm{a}}$ & $91.9^{\mathrm{b}}$ & 0.62 & 0.0002 \\
\hline $\mathrm{TDF}^{1}$ & $37.8^{\mathrm{a}}$ & $48.2^{\mathrm{a}}$ & $15.1^{\mathrm{b}}$ & $22.7^{\mathrm{b}}$ & 2.91 & 0.0001 \\
\hline $\mathrm{DE}^{1}$ & $89.0^{\mathrm{a}}$ & $81.3^{\mathrm{b}}$ & $82.8^{\mathrm{b}}$ & $81.2^{\mathrm{b}}$ & 0.75 & 0.0001 \\
\hline $\mathrm{ME}^{1}$ & $83.4^{\mathrm{a}}$ & $75.0^{\mathrm{b}}$ & $77.4^{\mathrm{b}}$ & $74.8^{\mathrm{b}}$ & 1.25 & 0.0001 \\
\hline
\end{tabular}

${ }^{1} \mathrm{DM}=$ dry matter; $\mathrm{TDF}=$ total dietary fiber; $\mathrm{DE}=$ digestible energy; $\mathrm{ME}=$ metabolizable energy.

${ }^{\mathrm{a}-\mathrm{c}}$ Means in the same row without common superscript letters denote a significant difference $(P<0.05)$.

\section{Apparent Total Tract Digestibility of Macronutrients and Energy}

Coefficients of ATTD for dogs fed the experimental diets are presented in Table 4. Dogs fed fiber-added diets had lower $(P<0.05)$ ATTD of DM (76.2, 77.2, and 79.6\%, respectively) and OM (80.9, 80.5 , and $79.9 \%$, respectively) when compared with the NF diet (DM: 85.4 and OM: 90.1\%). Fahey et al. (1990) reported a linear decrease in DM and $\mathrm{OM}$ digestibilities as $\mathrm{BP}$ inclusion increased from 0 to $12.5 \%$ in diets for adult dogs. In that study, the highest inclusion of BP (12.5\%) amounted to $13.7 \%$ $\mathrm{TDF}$, and DM and OM digestibilities of 84.3 and $87.6 \%$, respectively, were noted. More recently, Kroger et al. (2017) also reported an OM digestibility of $86.7 \%$ in dogs fed a diet containing $12 \%$ BP and 13.1\% TDF. Middelbos et al. (2007) noted ATTD of DM and OM of 85.4 and $83.2 \%$, and 91.0 and $88.7 \%$, respectively, for diets containing either 2.5\% BP or CL. Silvio et al. (2000) reported DM digestibility of $81.3 \%$ in dogs fed diets containing $10 \%$ CL. The lower coefficients for DM and OM observed in the current study might be attributed to the higher inclusion levels of BP and, consequently, greater TDF concentration $(17.3 \%)$. It is known that dietary fiber concentration may have a negative correlation with coefficients of ATTD digestibility of nutrients (Davidson and McDonald, 1998; Kienzle et al., 2001).

Dogs fed the NF and CL treatments had the greatest $(P<0.05)$ CP ATTD $(85.8$ and $87.1 \%$, respectively), followed by the $\mathrm{SBH}$ diet $(83.3 \%)$, with BP having the lowest value (78.8\%). Muir et al. (1996) reported similar CP digestibility by dogs fed CL (86.7\%). Although CP digestibility was lowest in dogs fed BP, BP is a fermentable fiber due to its greater soluble fiber content. This undoubtedly resulted in more microbial growth leading to more microbial $\mathrm{N}$ to be excreted in the feces, giving a false sense of undigested protein and resulting in lower apparent $\mathrm{CP}$ digestibility as suggested by Sunvold et al. (1995). Additionally, dietary fiber may also have an abrasive effect on the gastrointestinal tract increasing the elimination of sloughed cells in the feces and, as such, resulting in 
greater loss of endogenous proteins and lower $\mathrm{CP}$ ATTD (Wilfart et al., 2007). In contrast to our findings, Kroger et al. (2017) observed slightly greater CP digestibility by dogs fed BP (82.5\%); however, the diet fed had a lower TDF content (13\%). Cole et al. (1999), however, observed similar CP digestibility $(83.2 \%)$ by dogs fed an SBH diet containing $8.9 \% \mathrm{TDF}$. This suggests that $\mathrm{CP}$ digestibility could stabilize once SBH inclusion reaches a certain inclusion level.

Dogs fed the CL treatment had greater $(P<0.05)$ AHF ATTD $(94.3 \%)$ than those fed $\mathrm{NF}$, BP, and SBH treatments (90.9, 91.2, and 91.9\%, respectively). The greater AHF digestibility observed in dogs fed CL diet could be related to the greater concentration of AHF fat in this diet. Our findings are in contrast with previous literature supporting greater AHF digestibility (93.7-97.7\%) in adult dogs fed diets containing moderate or high levels of BP (Fahey et al., 1990, 1992; Kroger et al., 2017). Despite the higher concentration of TDF in the experimental diets in the current study, the source of fat used herein (i.e., choice white grease) also differed from most of the previous studies (e.g., chicken fat or vegetable oil). Thus, it is possible that not only the amount, but also the type of dietary fat affected our results. Previous research in puppies found that fat digestibility of beef tallow was dependent upon the unsaturated fatty acid concentration of the diet, with greater ratios of unsaturated to saturated fatty acids, resulting in a positive effect on digestibility (Meyer et al., 1992). Marx et al. (2015) also demonstrated that diets containing unsaturated fat sources had greater fat digestibility in dogs. For comparison, choice white grease has an unsaturated:saturated ratio of 0.31 , in contrast to 0.71 for poultry fat and 4.07 for soybean oil (NRC 2006).

Total dietary fiber digestibility was greatest in dogs fed the BP treatment $(48.2 \%)$, while NF was intermediate $(37.8 \%)$, and $\mathrm{CL}$ and $\mathrm{SBH}$ had the lowest TDF ATTD; $15.1 \%$ and $22.7 \%$, respectively. These are expected results because CL and $\mathrm{SBH}$ have a greater ratio of insoluble to soluble fiber (12.1:2.6 and 12.4:1.9). Slightly greater TDF digestibility was observed in dogs fed $\mathrm{SBH}$ at a $9 \%$ inclusion $(28.5 \%)$ and $\mathrm{BP}$ at a $12.5 \%$ inclusion level (57.5\%) (Fahey et al., 1990; Cole et al., 1999). Greater TDF digestibility was also observed by Fahey et al. (1992) when dogs were fed 7.5\% BP $(61.1 \%)$. The discrepancy among these findings could be possibility due to variations in the fiber composition of different sources of $\mathrm{SBH}$ and $\mathrm{BP}$. The TDF content of the SBH ingredient fed in the current study was $80.7 \%$ and an insoluble to soluble fiber ratio of 7:1. Previous research evaluated $\mathrm{SBH}$ TDF content of various sources that ranged from $63.8 \%$ to $81.2 \%$ and the ratio of insoluble to soluble fiber ranged from 5.0:1 to 15.4:1 (Cole et al., 1999). Insoluble fibers are less fermentable in the large intestine of monogastric animals, resulting in most of it being excreted in the feces. Soluble fibers are more easily fermented by microbes that harbor in the distal portions of the gastrointestinal tract. Thus, greater proportions of soluble, fermentable fibers will be degraded, resulting in subsequent greater TDF ATTD.

Digestible energy (DE) and ME were similar for dogs fed the three fiber-supplemented diets, but lower $(P<0.05)$ than for dogs fed the NF diet. Added dietary fiber dilutes the caloric density and may decrease nutrient digestibility (Weber et al., 2007), which is reflected in the DE and ME values for the fiber treatments. Cole et al. (1999) reported a slightly greater DE value for dogs fed 9\% $\mathrm{SBH}$ (87.4\%). Additionally, Fahey et al. (1992) observed greater $\mathrm{DE}$ and $\mathrm{ME}$ values for dogs fed $7.5 \% \mathrm{BP}$ (90.2 and $87.9 \%$, respectively). However, the diets in the mentioned literature did not approach the high TDF content of our experimental diets, which could result in the differences in DE and ME. However, this lower digestibility content is not a negative attribute. Greater inclusion levels of dietary fibers may improve satiety and have weight management applications, as suggested by Weber et al. (2007). With the continued increase in pet obesity, SBH may become a sustainable functional ingredient in diets targeting weight loss or management. However, future studies are warranted in this area.

\section{Fecal Fermentative End-Products}

Fecal fermentative end-products were affected by the different fiber sources added in the experimental diets (Table 5). It is assumed that the greater production of fermentative end-products measured in the feces is reflective of an augmented colonic fermentative process in the dog. Total SCFA concentration was greatest ( $\mu \mathrm{mol} / \mathrm{g}, \mathrm{DMB})$ for dogs fed $\mathrm{BP}$ and $\mathrm{SBH}$, indicating that there was increased saccharolytic fermentation occurring. Dogs fed NF and CL had lower $(P<0.05)$ total SCFA concentrations. Bosch et al. (2009) reported similar total SCFA production values in dogs fed a highly fermentable diet that contained $8.5 \%$ BP $(540 \mu \mathrm{mol} / \mathrm{g}$ $\mathrm{DMB})$ or a low fermentable diet that contained 8.5\% CL (260 $\mu \mathrm{mol} / \mathrm{g}$ DMB). Zentek (1996), 
Table 5. Fecal fermentative end-products for dogs fed diets containing select fiber sources

\begin{tabular}{|c|c|c|c|c|c|c|}
\hline \multirow[b]{2}{*}{ Item $(\mu \mathrm{mol} / \mathrm{g} \text { DM basis })^{1}$} & \multicolumn{4}{|c|}{ Treatments } & \multirow[b]{2}{*}{ SEM } & \multirow[b]{2}{*}{$P$-value } \\
\hline & No fiber & Beet pulp & Cellulose & Soybean hulls & & \\
\hline Fecal pH & $6.3^{\mathrm{a}}$ & $5.9^{\mathrm{b}}$ & $6.6^{\mathrm{a}}$ & $5.9^{\mathrm{b}}$ & 0.10 & 0.0001 \\
\hline Ammonia & $152.2^{\mathrm{a}}$ & $103.9^{\mathrm{b}}$ & $129.3^{\mathrm{ab}}$ & $147.8^{\mathrm{a}}$ & 11.53 & 0.0021 \\
\hline \multicolumn{7}{|l|}{ Phenols and indoles } \\
\hline Total phenols/indoles & $3.1^{\mathrm{a}}$ & $0.9^{\mathrm{b}}$ & $2.2^{\mathrm{a}}$ & $1.7^{\mathrm{ab}}$ & 0.48 & 0.0021 \\
\hline Phenol & 0.9 & 0.1 & 0.7 & 0.3 & 0.29 & 0.0862 \\
\hline Indole & $2.2^{\mathrm{a}}$ & $0.8^{\mathrm{b}}$ & $1.5^{\mathrm{ab}}$ & $1.4^{\mathrm{ab}}$ & 0.25 & 0.0019 \\
\hline \multicolumn{7}{|l|}{$S C F A^{1}$} \\
\hline Total SCFA ${ }^{1}$ & $267.0^{\mathrm{b}}$ & $582.5^{\mathrm{a}}$ & $251.1^{\mathrm{b}}$ & $479.7^{\mathrm{a}}$ & 41.43 & 0.0001 \\
\hline Acetate & $150.8^{\mathrm{b}}$ & $411.9^{\mathrm{a}}$ & $156.9^{\mathrm{b}}$ & $321.0^{\mathrm{a}}$ & 28.48 & 0.0001 \\
\hline Propionate & $82.6^{\mathrm{b}}$ & $125.1^{\mathrm{a}}$ & $70.3^{\mathrm{b}}$ & $121.0^{\mathrm{a}}$ & 10.56 & 0.0003 \\
\hline Butyrate & $33.5^{\mathrm{ab}}$ & $45.5^{\mathrm{a}}$ & $23.8^{\mathrm{b}}$ & $37.7^{\mathrm{ab}}$ & 4.91 & 0.0037 \\
\hline \multicolumn{7}{|l|}{$B C F A^{l}$} \\
\hline Total $\mathrm{BCFA}^{1}$ & $22.9^{\mathrm{a}}$ & $12.1^{\mathrm{b}}$ & $17.1^{\mathrm{b}}$ & $17.0^{\mathrm{b}}$ & 1.51 & 0.0003 \\
\hline Isobutyrate & $8.8^{\mathrm{a}}$ & $4.7^{\mathrm{b}}$ & $6.6^{\mathrm{ab}}$ & $6.3^{\mathrm{b}}$ & 0.59 & 0.0009 \\
\hline Isovalerate & $13.3^{\mathrm{a}}$ & $6.1^{\mathrm{c}}$ & $9.8^{\mathrm{b}}$ & $9.8^{\mathrm{b}}$ & 0.97 & 0.0001 \\
\hline Valerate & $0.8^{\mathrm{ab}}$ & $1.3^{\mathrm{a}}$ & $0.7^{\mathrm{b}}$ & $0.9^{\mathrm{ab}}$ & 0.13 & 0.0121 \\
\hline
\end{tabular}

${ }^{1} \mathrm{DM}=$ dry matter; SCFA $=$ short-chain fatty acids; $\mathrm{BCFA}=$ branched-chain fatty acids

${ }^{\mathrm{a}-\mathrm{c}}$ Means in the same row without common superscript letters denote a significant difference $(P<0.05)$.

however, observed lower total SCFA production (194 $\mu \mathrm{mol} / \mathrm{g})$ when feeding dogs a CL diet with similar TDF content $(13.7 \%)$. Dogs fed BP and SBH had greater $(P<0.05)$ acetate and propionate concentrations than dogs fed the NF and CL treatments. Kroger et al. (2017) reported slightly lower values for acetate $(214 \mu \mathrm{mol} / \mathrm{g})$ and propionate $(64.8 \mu \mathrm{mol} / \mathrm{g})$ in dogs fed diets containing $12 \% \mathrm{BP}$ (13.1\% TDF). Lower acetate (127 and $276 \mu \mathrm{mol} / \mathrm{g})$ and propionate (49 and $93 \mu \mathrm{mol} / \mathrm{g}$ ) concentrations were also observed by Middelbos et al. (2007) in dogs fed CL and BP diets. However, CL and BP were only added at a $2.5 \%$ inclusion level in the previously mentioned study (5.07 and 4.03\% TDF, respectively). Dogs fed the BP treatment had the greatest $(P<0.05)$ butyrate concentration $(45.5 \mu \mathrm{mol} / \mathrm{g})$, while NF and SBH had intermediate concentration (33.5 and $37.7 \mu \mathrm{mol} / \mathrm{g}$, respectively), and CL having the lowest value $(23.8 \mu \mathrm{mol} / \mathrm{g})$. Butyrate is preferentially taken up by the colonocytes compared with acetate and propionate. Butyrate provides energy to the colonocytes as well as having potential protective qualities against diseases, such as ulcerative colitis as observed in humans (Christl et al., 1996). Not only did BP and SBH result in greater amounts of fecal SCFA, they resulted in similar proportions of acetate $(70.7$ and $66.9 \%)$, propionate $(21.5$ and $25.2 \%$ ), and butyrate $(7.8$ and $7.9 \%$ ) of the total SCFA produced.

Total phenol and indole concentrations $(\mu \mathrm{mol} / \mathrm{g}, \mathrm{DMB})$ were greatest $(P<0.05)$ in dogs fed
$\mathrm{NF}$ and CL treatments (3.1 and $2.2 \mu \mathrm{mol} / \mathrm{g}$, respectively). Intermediate concentrations $(1.7 \mu \mathrm{mol} / \mathrm{g})$ resulted from $\mathrm{SBH}$ feeding, whereas $\mathrm{BP}$ had the lowest concentration of total phenols and indoles $(0.9 \mu \mathrm{mol} / \mathrm{g})$. The highest concentrations of ammonia were observed in dogs fed the $\mathrm{NF}$ and $\mathrm{SBH}$ treatments $(152.2$ and $147.8 \mu \mathrm{mol} / \mathrm{g})$, and lowest (103.9 $\mu \mathrm{mol} / \mathrm{g}$ ) for dogs fed BP, whereas dogs fed the CL treatment had similar ammonia concentration $(129.3 \mu \mathrm{mol} / \mathrm{g})$ when compared with all other treatments. BP and SBH had the lowest fecal $\mathrm{pH}$, which has been seen to reduce the resorption of ammonia (Matsuoka et al., 1990). Phenols, indoles, ammonia, and BCFA are putrefactive compounds that result from bacterial fermentation in the hindgut and causes foul-smelling feces, which can be an unappealing quality to a diet from the pet owner's standpoint (Miner and Hazen, 1969; O'Neill and Phillips, 1992). The amount of putrefactive compounds that are produced depends on the amount and type of fiber present in the diet (Vince et al., 1990; Flickinger et al., 2003). Increased amounts of rapidly fermentable fibers, such as pectins, have been observed to cause an increase in peptides and amino acids produced in the proximal colon, followed by microbes fermenting these substrates leading to the formation of these undesirable putrefactive compounds (Barry et al., 2010; Kanakupt et al., 2011).

Branched-chain fatty acids are produced when energy is limited in the colon (Middelbos et al., 
2007). Total BCFA concentrations were significantly greater $(P<0.05)$ in dogs fed the NF treatment compared with the three fiber treatments, possibly indicating limited energy available in the large intestine. Dogs fed NF had the greatest $(P<0.05)$ isobutyrate concentrations $(8.8 \mu \mathrm{mol} / \mathrm{g})$, whereas $C L$ was observed to have intermediate concentrations $(6.6 \mu \mathrm{mol} / \mathrm{g})$, and dogs fed $\mathrm{BP}$ and $\mathrm{SBH}$ contained the lowest isobutyrate concentrations (4.7 and $6.3 \mu \mathrm{mol} / \mathrm{g}$, respectively). NF also had the greatest $(P<0.05)$ isovalerate concentration $(13.3 \mu \mathrm{mol} / \mathrm{g})$, while CL and SBH had intermediate concentrations (both containing $9.8 \mu \mathrm{mol} / \mathrm{g}$ ), and BP had the lowest concentration $(6.1 \mu \mathrm{mol} / \mathrm{g})$. Dogs fed BP had the greatest $(P<0.05)$ valerate concentration $(1.3 \mu \mathrm{mol} / \mathrm{g})$, while no differences were observed among dogs fed NF, CL, and SBH diets $(0.8,0.7$, and $0.9 \mu \mathrm{mol} / \mathrm{g})$. Kroger et al. (2017) observed similar isovalerate $(6.0 \mu \mathrm{mol} / \mathrm{g})$, isobutyrate $(4.5 \mu \mathrm{mol} / \mathrm{g})$, and valerate $(0.5 \mu \mathrm{mol} / \mathrm{g})$ concentrations in dogs fed $12 \%$ BP. Overall, SBH diet resulted in low concentrations of these putrefactive compounds, with fecal concentrations mirroring of dogs fed BP, thus highlighting the benefits of SBH as a dietary fiber source.

\section{Implications}

On the basis of the results of this study, dogs fed SBH as a dietary fiber source had similar ATTD of macronutrients when compared with the other two fiber treatments, BP and CL. Dogs tolerated the SBH dietary treatment well, and there were no detrimental effects on fecal quality or health status. Additionally, dogs fed SBH had a beneficial shift in fecal fermentative end-products when compared with the CL and NF diets; SCFA concentrations increased while phenols, indoles, and BCFA concentrations decreased. Although the SBH diet had a greater insoluble:soluble fiber ratio than CL, the results of this study indicated that the $\mathrm{SBH}$ diet was comparable with the $\mathrm{BP}$ diet, suggesting that the insoluble fraction of SBH might be more fermentable than CL. On the basis of the findings of this research, SBH can be used as an economical, readily available, and sustainable dietary fiber source in pet food formulations for adult dogs, even when fed at high concentrations of approximately $15 \%$ TDF. Soybean hulls has the potential to be a functional ingredient in diets for dogs, showing similar beneficial fermentative profile to beet pulp, it may also aid in weight management by reducing caloric density of canine diets. Further studies should be conducted to confirm this hypothesis.
Conflict of interest statement. Dr. Gary M. Davenport is an employee of ADM Company, which partially funded this research.

\section{LITERATURE CITED}

American Association of Cereal Chemists (AACC). 1983. Approved methods. 8th ed. AACC, St. Paul, MN.

American Pet Products Association. 2018. APPA National Pet Owners Survey Statistics: pet ownership and annual expenses. 2017-2018 survey. http://www.americanpetproducts.org/press_industrytrends.asp (accessed 14 January 2018).

American Veterinary Medical Association. 2012. US pet ownership and demographics sourcebook. 2012. American Veterinary Medical Association, Schaumburg, IL, USA.

AOAC. 1995. Official methods of analysis. 16th ed. AOAC, Arlington, VA.

AOAC. 2006. Official methods of analysis. 17th ed. AOAC, Arlington, VA.

Banta, C. A., E. T. Clemens, M. M. Krinsky, and B. E. Sheffy. 1979. Sites of organic acid production and patterns of digesta movement in the gastrointestinal tract of dogs. J. Nutr. 109:1592-1600. doi:10.1093/jn/109.9.1592

Barry, K. A., B. J. Wojcicki, I. S. Middelbos, B. M. Vester, K. S. Swanson, and G. C. Fahey, Jr. 2010. Dietary cellulose, fructooligosaccharides, and pectin modify fecal protein catabolites and microbial populations in adult cats. J. Anim. Sci. 88:2978-2987. doi:10.2527/jas.2009-2464

den Besten, G., K. van Eunen, A. K. Groen, K. Venema, D. J. Reijngoud, and B. M. Bakker. 2013. The role of shortchain fatty acids in the interplay between diet, gut microbiota, and host energy metabolism. J. Lipid Res. 54:2325-2340. doi:10.1194/jlr.R036012

Bosch, G., A. Verbrugghe, M. Hesta, J. J. Holst, A. F. van der Poel, G. P. Janssens, and W. H. Hendriks. 2009. The effects of dietary fibre type on satiety-related hormones and voluntary food intake in dogs. Br. J. Nutr. 102:318-325. doi:10.1017/S0007114508149194

Budde, E. F. 1952. The determination of fat in baked biscuit type of dog foods. J. AOAC. 35:799-805.

Burkhalter, T. M., N. R. Merchen, L. L. Bauer, S. M. Murray, A. R. Patil, J. L. Brent, Jr, and G. C. Fahey, Jr. 2001. The ratio of insoluble to soluble fiber components in soybean hulls affects ileal and total-tract nutrient digestibilities and fecal characteristics of dogs. J. Nutr. 131:1978-1985. doi:10.1093/jn/131.7.1978

Chaney, A. L., and E. P. Marbach. 1962. Modified reagents for determination of urea and ammonia. Clin. Chem. 8:130-132.

Christl, S. U., H. D. Eisner, G. Dusel, H. Kasper, and W. Scheppach. 1996. Antagonistic effects of sulfide and butyrate on proliferation of colonic mucosa: a potential role for these agents in the pathogenesis of ulcerative colitis. Dig. Dis. Sci. 41:2477-2481.

Cole, J. T., G. C. Fahey, Jr, N. R. Merchen, A. R. Patil, S. M. Murray, H. S. Hussein, and J. L. Brent, Jr. 1999. Soybean hulls as a dietary fiber source for dogs. J. Anim. Sci. 77:917-924.

Davidson, M. H., and A. McDonald. 1998. Fiber forms and functions. Nutr. Res. 18:617-624. doi:10.1016/ S0271-5317(98)00048-7 
Erwin, E. S., G. J. Marco, and E. M. Emery. 1961. Volatile fatty acid analyses of blood and rumen fluid by gas chromatography. J. Dairy Sci. 44:1768-1771.

Fahey, G. C., Jr, N. R. Merchen, J. E. Corbin, A. K. Hamilton, K. A. Serbe, and D. A. Hirakawa. 1990. Dietary fiber for dogs: II. Iso-total dietary fiber (TDF) additions of divergent fiber sources to dog diets and their effects on nutrient intake, digestibility, metabolizable energy and digesta mean retention time. J. Anim. Sci. 68:4229-4235.

Fahey, G. C., Jr, N. R. Merchen, J. E. Corbin, A. K. Hamilton, L. L. Bauer, E. C. Titgemeyer, and D. A. Hirakawa. 1992. Dietary fiber for dogs: III. Effects of beet pulp and oat fiber additions to dog diets on nutrient intake, digestibility, metabolizable energy, and digesta mean retention time. J. Anim. Sci. 70:1169-1174.

Flickinger, E. A., E. M. Schreijen, A. R. Patil, H. S. Hussein, C. M. Grieshop, N. R. Merchen, and G. C. Fahey, Jr. 2003. Nutrient digestibilities, microbial populations, and protein catabolites as affected by fructan supplementation of dog diets. J. Anim. Sci. 81:2008-2018. doi:10.2527/2003.8182008x

Kanakupt, K., B. M. Vester Boler, B. R. Dunsford, and G. C. Fahey, Jr. 2011. Effects of short-chain fructooligosaccharides and galactooligosaccharides, individually and in combination, on nutrient digestibility, fecal fermentative metabolite concentrations, and large bowel microbial ecology of healthy adults cats. J. Anim. Sci. 89:1376-1384. doi:10.2527/jas.2010-3201

Kienzle, E., I. Schrag, R. Butterwick, and B. Opitz. 2001. Calculation of gross energy in pet foods: new data on heat combustion and fibre analysis in a selection of foods for dogs and cats. J. Anim. Physiol. Anim. Nutr. (Berl). 85:148-157.

Kröger, S., W. Vahjen, and J. Zentek. 2017. Influence of lignocellulose and low or high levels of sugar beet pulp on nutrient digestibility and the fecal microbiota in dogs. J. Anim. Sci. 95:1598-1605. doi:10.2527/jas.2016.0873

Marx, F. R., L. Trevizan, Ø. Ahlstrøm, and A. M. Kessler. 2015. Soybean oil and beef tallow in dry extruded diets for adult dogs. Arch. Anim. Nutr. 69:297-309. doi:10.108 0/1745039X.2015.1058619

Massimino, S. P., M. I. McBurney, C. J. Field, A. B. Thomson, M. Keelan, M. G. Hayek, and G. D. Sunvold. 1998. Fermentable dietary fiber increases GLP-1 secretion and improves glucose homeostasis despite increased intestinal glucose transport capacity in healthy dogs. J. Nutr. 128:1786-1793. doi:10.1093/jn/128.10.1786

Matsuoka, Y., T. Uruno, M. Yamada, A. Mizukami, Y. Kanetake, N. Sunagane, and K. Kubota. 1990. [Effects of lactulose on blood ammonia levels in beagles with end-to-side portacaval shunt]. Nihon Yakurigaku Zasshi. 96:97-101.

Meyer, H., J. Zentek, and U. Freudenthal. 1992. Digestibility of beef tallow in dogs. Wien. Tierartz. Monat. 79:202-207.

Middelbos, I. S., N. D. Fastinger, and G. C. Fahey, Jr. 2007. Evaluation of fermentable oligosaccharides in diets fed to dogs in comparison to fiber standards. J. Anim. Sci. 85:3033-3044. doi:10.2527/jas.2007-0080

Miner, J. R., and T. E. Hazen. 1969. Ammonia and amines: components of swine building odor. Trans. ASAE. 12:772-774.
Muir, H. E., S. M. Murray, G. C. Fahey, Jr, N. R. Merchen, and G. A. Reinhart. 1996. Nutrient digestion by ileal cannulated dogs as affected by dietary fibers with various fermentation characteristics. J. Anim. Sci. 74:1641-1648.

National Research Council. 2006. Nutrient requirements of dogs and cats. 2nd ed. National Academies Press, Washington, DC.

O’Neill, D. H., and V. R. Phillips. 1992. A review of the control of odour nuisance from livestock buildings: part 3. Properties of the odorous substances which have been identified in livestock wastes or in the air around them. J. Agric. Eng. Res. 53:23-50. doi:10.1016/0021-8634(92)80072-Z

Scheraiber, M., T. T. Sabchuk, J. R. da Silva, L. P. Domingues, T. A. Ramos, A. P. Félix, S. G. de Oliveria, and A. V. F. de Silva. 2016. Effect of soybean hulls on blood biochemical profiles and body condition of dogs. R. Bras. Zootec. 45:755-759. doi:10.1590/ s1806-92902016001200004

Serena, A., H. Jørgensen, and K. E. Bach Knudsen. 2008. Digestion of carbohydrates and utilization of energy in sows fed diets with contrasting levels and physicochemical properties of dietary fiber. J. Anim. Sci. 86:2208-2216. doi:10.2527/jas.2006-060

Silvio, J., D. L. Harmon, K. L. Gross, and K. R. McLeod. 2000. Influence of fiber fermentability on nutrient digestion in the dog. Nutrition. 16:289-295.

Sunvold, G. D., H. S. Hussein, G. C. Fahey, Jr, N. R. Merchen, and G. A. Reinhart. 1995. In vitro fermentation of cellulose, beet pulp, citrus pulp, and citrus pectin using fecal inoculum from cats, dogs, horses, humans, and pigs and ruminal fluid from cattle. J. Anim. Sci. 73:3639-3648.

Swanson, K. S., C. M. Grieshop, E. A. Flickinger, L. L. Bauer, H. P. Healy, K. A. Dawson, N. R. Merchen, and G. C. Fahey, Jr. 2002. Supplemental fructooligosaccharides and mannanoligosaccharides influence immune function, ileal and total tract nutrient digestibilities, microbial populations and concentrations of protein catabolites in the large bowel of dogs. J. Nutr. 132:980-989. doi:10.1093/ jn/132.5.980

United States Department of Agriculture. 2017. Related data and statistics. www.ers.usda.gov/topics/crops/soybeansoil-crops/related-data-statistics/. (accessed 14 October 2017).

Vince, A. J., N. I. McNeil, J. D. Wager, and O. M. Wrong. 1990. The effect of lactulose, pectin, arabinogalactan and cellulose on the production of organic acids and metabolism of ammonia by intestinal bacteria in a faecal incubation system. Br. J. Nutr. 63:17-26.

Weber, M., T. Bissot, E. Servet, R. Sergheraert, V. Biourge, and A. J. German. 2007. A high-protein, high-fiber diet designed for weight loss improves satiety in dogs. J. Vet. Intern. Med. 21:1203-1208. doi:10.1111/j.1939-1676.2007. tb01939.x

Wilfart, A., L. Montagne, P. H. Simmins, J. van Milgen, and J. Noblet. 2007. Sites of nutrient digestion in growing pigs: effect of dietary fiber. J. Anim. Sci. 85:976-983. doi:10.2527/jas.2006-431

Zentek, J. 1996. Cellulose, pectins and guar gum as fibre sources in canine diets. J. Anim. Physiol. Anim. Nutr. 75:36-45. doi:10.1111/j.1439-0396.1996.tb00674.x 